\title{
Modeling of wildfire occurrence by using climate data and effect of temperature increments
}

Amir Hossein Sadat Razavi ${ }^{1}$, Majid Shafiepour Motlagh ${ }^{1}$, Alireza Noorpoor ${ }^{1}$, Amir Houshang Ehsani $^{1}$

$5 \quad{ }^{1}$ Department of Environmental Engineering, University of Tehran, Tehran, Iran

Correspondence to: Majid Shafiepour Motlagh (shafiepourm@yahoo.com, shafiepour@ut.ac.ir)

Amir Hossein Sadat Razavi: sadatrazavi@ut.ac.ir,ahsrazavi@gmail.com

Majid Majid Shafiepour Motlagh: shafiepourm@yahoo.com, shafiepour@ut.ac.ir

Alireza Noorpoor: noorpoor@ut.ac.ir

Amir Houshang Ehsani: ehsani@ut.ac.ir 


\begin{abstract}
Forest fires are assumed as one of the key natural hazards in the globe since it causes great losses in ecology, economy, and human lives; recent fire cases in US and their vast damages are vivid reasons to study the wildfires more deeply One of the basic requirements to manage the threats and protect wildlife is the ability to predict wildfire spots which is necessary to prioritize forest management. In this study, a 25 -year period natural wildfire database and a wide array of environmental variables are used to develop an artificial neural network model with the aim of predicting potential fire spots. This study focuses on non-human reasons of wildfires (natural) to compute global warming effects on wildfires. Among the environmental variables, this study shows the significance of temperature for predicting wildfire cases while other parameters are presented in the next study. The study area of this study includes all forest fire cases in united states from 1992 to 2015 excluding tropical forests. The data of eight days including the day fire occurred and 7 previous days are used as input to the model to forecast fire occurrence probability of that day. The climatic inputs are extracted from ECMWF. The inputs of the model are temperature at 2 meter above surface, relative humidity, Total pressure, evaporation, volumetric soil water layer 1, snow melt, Keetch-Byram drought index, total precipitation, wind speed (along $\mathrm{U}$ and $\mathrm{V}$ direction), and NDVI. The results show there is a transient temperature span for each forest type which acts like a threshold to predict fire occurrence. In Temperate forests, A 0.1-degree Celsius increase in temperature relative to 7-day average temperature before a fire occurrence results in prediction model output of greater than 0.8 for $4.75 \%$ of fire forest cases. In Boreal forests, the model output for temperature increase of less than 1 degree relative to past 7-day average temperature represents no chance of wildfire. But the non-zero fire forest starts at 2 degrees increase of temperature which ends to $2.62 \%$ of fire forest cases with model output of larger than 0.8 . It is concluded that other variables except temperature are more determinant to predict wildfires in temperate forests rather than in boreal forests.
\end{abstract}

\title{
1. Introduction
}

Forest ecosystems are dynamic due to wildfires which can formatively shape vegetation distribution, structure, and composition in many systems (Vilà-Vilardell et al., 2020). One of the most serious natural disasters that threaten the ecosystem is forest fires (Hamadeh et al., 2017). Forest fires have come to attention globally since they can cause great ecological, economic and humanitarian losses (Dey \& Schweitzer, 2018; Spessa et al., 2015; Vilar et al., 2019). The more wildfires happen worldwide, the more losses to human lives and natural resources happen (Davis et al., 2017; Dennison et al., 2014; Hamadeh et al., 2017; Jahdi et al., 2016; Littell et al., 2009; Pérez-Sánchez et al., 2017; Srivas et al., 2017; Stavros et al., 2014). The recent fire cases in US have caused severe 
damage to urban and natural land uses; the volume of the damage is studied by scholars which reveals every detail of the losses.

Policy makers need to examine climate change and its effect for fire management (North et al., 2015). Accurate monitor of wildfire risk condition is one of the most common prerequisites to conservatively preserve forest wildfires (Flannigan et al., 2013; Vilar et al., 2019). The first step for monitoring is to develop a prediction model to provide information for resources allocation to fuel treatments (Jaafari et al., 2017; Nami et al., 2018; Parisien et al., 2016). The application of prediction models is based on an assumption that similar local conditions are more likely to result in future similar ignitions (Catry et al., 2009; Jaafari, Zenner, et al., 2019).

Fire activity is predicated to increase globally in wildland due to climate change (Flannigan et al., 2009; Seidl et al., 2017).

Fire regimes have been dominated by weather events which are uncontrolled due to changes in fire suppression and land-use, and climate warming (Duane et al., 2019; Jolly et al., 2015; San-Miguel-Ayanz et al., 2013). CO2 emission due to forest wildfire and climate change area exacerbated by each other in a positive feedback loop (Hamadeh et al., 2017; Ramanathan \& Carmichael, 2008). Researchers believe climate change act as one of the main drivers in forecasting ecosystem change for the next decades (Abatzoglou \& Kolden, 2013; Abatzoglou \& Williams, 2016; Aponte et al., 2016; Moritz et al., 2012). Climatic changes along with socioeconomic changes can alter fuel composition, loading, and connectivity which will in turn affect fire regimes (Hessl, 2011).

In this study, the effect of climatic changes on wildfire hazard is identified based on use updated fire observations during a 23-year period and a wide array of environmental variables to develop an artificial neural network model with the aim of predicting potential fire spots. This study focuses on non-human reasons of wildfires (natural) to compute global warming effects on wildfires.

\section{Study area and data used}

\subsection{Study area}

65 The study area of this study includes all forest fire cases in United States from 1992 to 2015. The fire spots spread almost all over the United States (Short, 2017).

\subsection{Data used}

The fire cases in this study were acquired from a research data archive supplied by U.S. Department of Agriculture (USDA). The data were retrieved from the database (Short, 2017). The database was published with the title of 

United States from 1992 to 2015 (Short, 2017). It is a part of the national Fire Program Analysis (FPA) system. The data is acquired by reporting systems of federal, state, and local fire organizations.

For this project, we chose to acquire fire records from 1992 to 2015 only. Besides, only those fires records with burnt area of greater than $1 \mathrm{~km}^{\wedge} 2$ area examined. One of the precious attributes of the database is the cause of each fire records which shows whether the fire was initiated by a natural or man-made reason. Due to the objective of this study, the fire records with man-made origin were excluded.

Based on the aforementioned explanation, 18204 fire records were extracted from the database.

\section{Method and data}

\section{1. method}

Logistic regression is a common tool in some studies (e.g. Catry et al., 2009; Jaafari, Mafi-Gholami, et al., 2019). There are also other common methods like support vector machine (SVM), random forest, and neural network in this regard (Jaafari et al., 2018).

This study introduces a model to predict probable wildfire hotspot using weather condition parameters of a specific day and of a few days before that. We take data of eight days including the day and 7 previous days to forecast fire occurrence probability of that day.

The dataset used for model development includes wildfires occurred in USA during 1992 to 2015 and climatic parameters extracted from ECMWF.

\subsection{Sample generation or Source Database}

Due to lack of sufficiency and unavailability of directly measured weather and climate data from synoptic stations in most of the forest in the world, we used the weather parameters computed by weather models and presented by ECMWF. This study also is checking the power and reliability of these data for wildfire prediction.

Using the data of ECMWF, we take the "ERA5 from 1979 to present" database for the input of the model development.

According to the document of this database, "ERA5 is the fifth generation ECMWF atmospheric reanalysis of the and consistent dataset using the laws of physics (ECMWF)." 
There are the features that make the database suitable for this study. It provides the relevant data computed daily at 12 PM GMT.

The data set of the detected wildfires is generated by USDA (United States Department of Agriculture) through which the data for 1992 to 2015 was extracted (https://www.fs.usda.gov/rds/archive/catalog/RDS-2013-0009.4) About one third of the land surfaces of the world is covered by forests. They are categorized based on their distance from the equator. There are different types of forests, but some share common traits based on the local climate. There are four categories into which forests can fit: tropical, subtropical, temperate, and boreal.

We focused on the United States of America forest due to complete and accessibility of this data over the years from 1992 to 2015.

The wildfires occurred in tropical forests were outside of the scope and hence were excluded from the data, while the fires occurred in Alaska are taken to happen in boreal forest and the others in other states to happen in temperate forest. Therefore, about 18204 wildfires happened in temperate and boreal forests. In order to introduce the non-fire cases, the weather condition of 30 days before each fire case is assumed as non-fire case. 


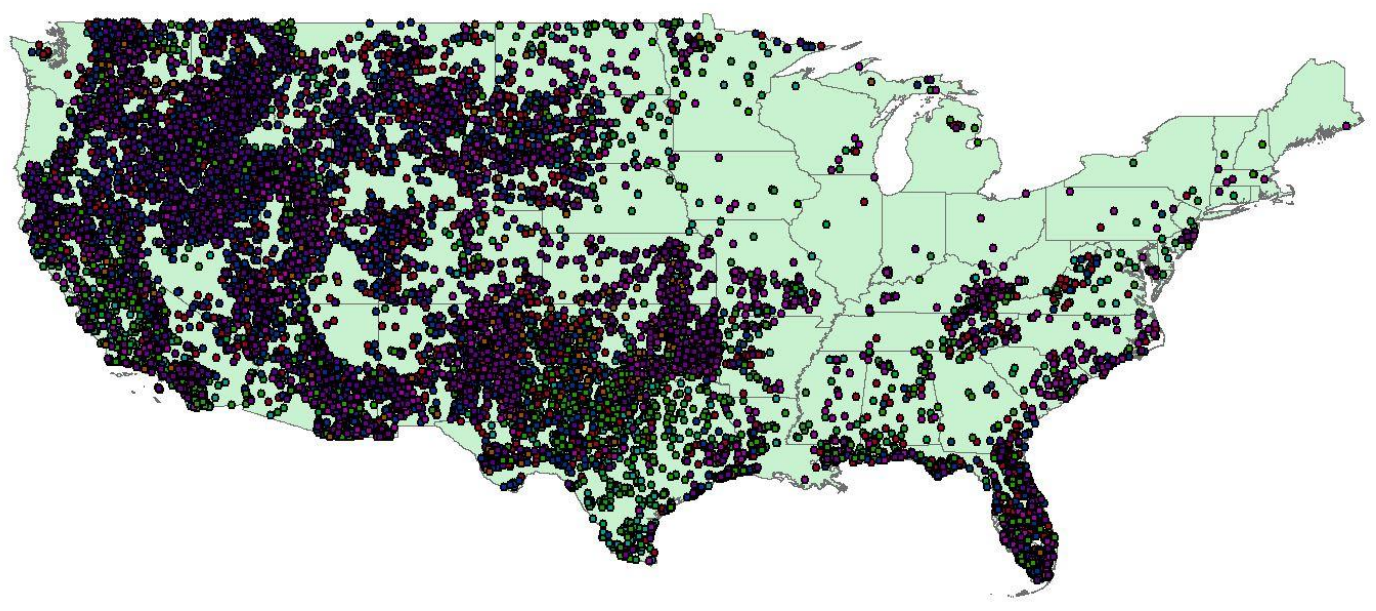

8

(a) All states except Alaska

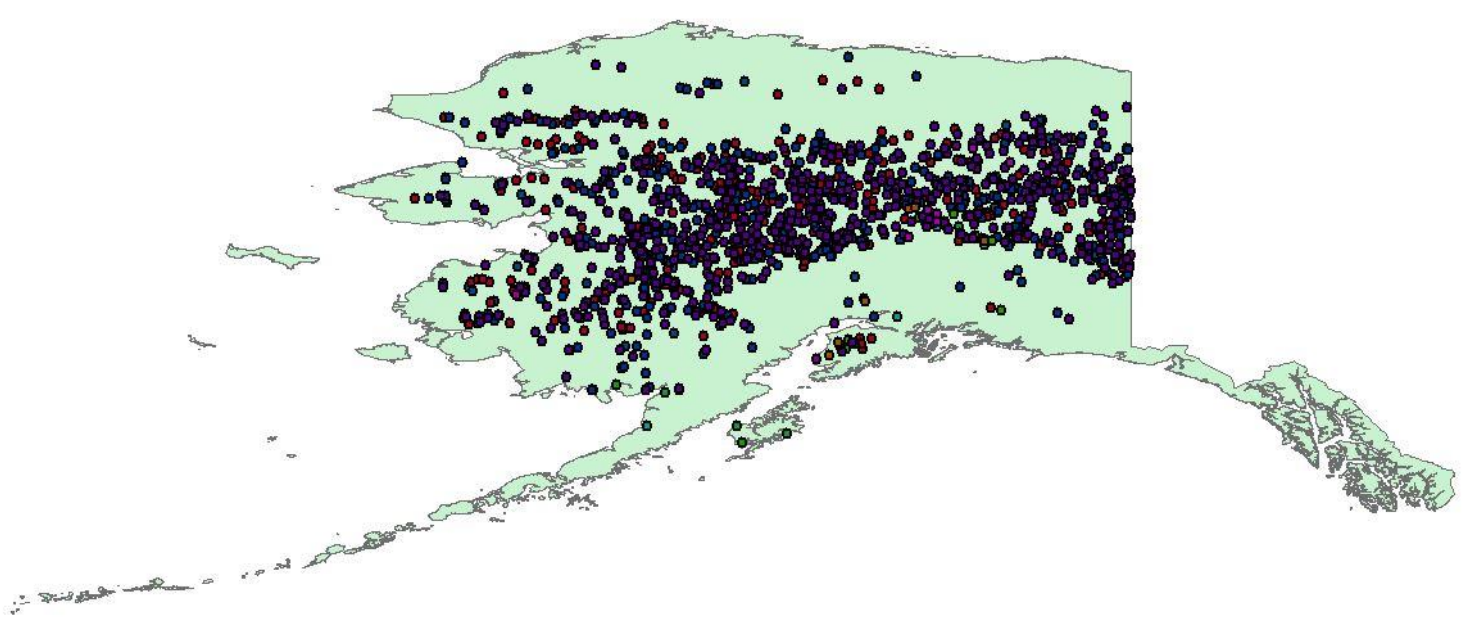

(b) Alaska

Figure 1: The map of USA and events location 


\subsection{Feature selection}

We take temperature at 2 meters above surface, relative humidity, total pressure, evaporation, volumetric soil water layer 1, snow melt, Keetch-Byram drought index, total precipitation, wind speed (along U and V direction), and NDVI as 11 effective independent variables. The variables are described in Table 1.

Table 1: Input variables to ANN

\begin{tabular}{|c|c|c|}
\hline Parameter name & Unit & Description \\
\hline Relative Humidity & $\%$ & $\begin{array}{c}\text { At saturation point, water vapor has equilibrium vapor pressure. } \\
\text { Relative humidity shows the ration of actual vapor pressure over } \\
\text { equilibrium vapor pressure at a given temperature. }\end{array}$ \\
\hline $\begin{array}{l}\text { Keetch-Byram } \\
\text { drought index }\end{array}$ & Dimensionless & $\begin{array}{l}\text { There is a direct correlation between upper soil moisture } \\
\text { deficiency and wildfire risk and The Keetch-Byram drought index } \\
\text { (KBDI) was introduced this purpose. }\end{array}$ \\
\hline wind speed & $\mathrm{m} / \mathrm{s}$ & $\begin{array}{l}\text { Wind speed in both directions are examined in this study. The U } \\
\text { and V parameters show wind speed in eastward direction and } \\
\text { northward direction respectively. A negative value means the } \\
\text { direction of wind in the opposite direction stated in the definition. }\end{array}$ \\
\hline $2 \mathrm{~m}$ temperature & $\mathrm{K}$ & Temperature at 2 meters above surface \\
\hline Evaporation & $\begin{array}{l}\mathrm{m} \text { of water } \\
\text { equivalent }\end{array}$ & $\begin{array}{l}\text { The amount of evaporated water from the Earth's surface is } \\
\text { accumulated in the parameter. It also includes transpiration. }\end{array}$ \\
\hline $\begin{array}{l}\text { NDVI (Normalized } \\
\text { Difference } \\
\text { Vegetation Index) }\end{array}$ & Dimensionless & $\begin{array}{l}\text { NDVI is a measure of plant health and density. The index is } \\
\text { computed using remote sensing images like satellite images. the } \\
\text { range of NDVI is between }-1 \text { to }+1 \text {. Values close to }+1 \text { shows } \\
\text { healthy and dense vegetation. }\end{array}$ \\
\hline Total pressure & $\mathrm{Pa}$ & $\begin{array}{l}\text { Atmospheric pressure of air at a specific elevation which is also } \\
\text { known as barometric pressure. }\end{array}$ \\
\hline $\begin{array}{l}\text { Volumetric soil } \\
\text { water layer } 1\end{array}$ & $m^{3} / m^{3}$ & $\begin{array}{c}\text { Based on ECMWF Integrated Forecasting System model, layer } 1 \\
\text { of soil includes top } 7 \mathrm{~cm} \text { layer from surface. The volumetric soil } \\
\text { water shows the volume of water in the soil layer }\end{array}$ \\
\hline Snowmelt & $\begin{array}{l}\mathrm{m} \text { of water } \\
\text { equivalent }\end{array}$ & $\begin{array}{l}\text { It shows how much water the snowpack contains. It is also known } \\
\text { as Snow Water Equivalent (SWE). In other words, the water } \\
\text { acquired from melting entire snowpack equals SWE. }\end{array}$ \\
\hline Total Precipitation & $\mathrm{m}$ & $\begin{array}{l}\text { This parameter shows total amount of water either as rain or snow } \\
\text { falling on the surface }\end{array}$ \\
\hline
\end{tabular}

In the first step, data was normalized by the "standard score" method.

\subsection{Neural Networks}

125 The architecture of proposed Artificial neural networks (ANN) includes one hidden layer and one output layer. $60 \%$ of data is used for training, $20 \%$ for validation and $20 \%$ for testing 
The training algorithm is "Levenberg-Marquardt" method.

\section{Result}

In this study, the model was developed using Artificial Neural Network to predict wildfire cases based on temperature variation. The dataset used for train, validation, and test of the model was provided by the history record of wildfires in US from 1992 to 2015 (Karen C., 2017). The large, destructive, uncontrolled, quick (rapid spread), self-Induced, unplanned, and unwanted wildfire cases were selected which include 18204 cases. The same number of non-fire cases were also extracted; it is assumed no fire has occurred one month before each 18204 records extracted as the wildfire cases at the same location. Both 18204 wildfire cases and 18204 non-fire cases were imported to the ANN. All cases were categorized based on their forest type (whether temperate or boreal) and processed separately.

The predictive variables including temperature (at 2 meters above surface), relative humidity, absolute pressure, evaporation, soil moisture, snow storage, Keetch-Byram drought index, precipitation, wind speed, and NDVI were taken from ECMWF (European Centre for Medium-Range Weather Forecasts1); the full data is available online. The difference between each parameter and the past 7-day average before fire start was computed; except for NDVI. Due to small variation of NDVI during 7 days, its 7-day average was directly used in the model. Each parameter was normalized using the following formula:

$\underline{\text { data-average }}$

The same process was performed for parameters of non-fire cases.

The ANN model was independently trained for each forest type (temperate or boreal).

The model should predict fire spots based on weather data to supply basic information decisive for relevant organizations to take necessary actions required for fire management.

The model output is a decimal number which can be interpreted as the potential of fire occurrence. The values greater than or equal to 1 states absolute fire while the values less than or equal to 0 states there is definitely no fire. The range between 0 and 1 is divided to three parts:

a. For values greater than or equal to 0.8 , a warning attention should be sent to responsible organizations.

b. No attention is necessary for values less than 0.5 .

\footnotetext{
${ }^{1}$ https://cds.climate.copernicus.eu/
} 
c. The points with values between 0.5 and 0.8 should be monitored during the next few days.

\section{Temperate forests}

Among the different algorithms in ANN, Levenberg-Marquartdt had the best performance with regression factor of 9.8e-1 and MSE of 1.01e-2. Half of the data set related to temperate forests were used for network training; 25 percent of the data set were used in validation and the rest were used for testing step. Figure 2 represents regression in each step.
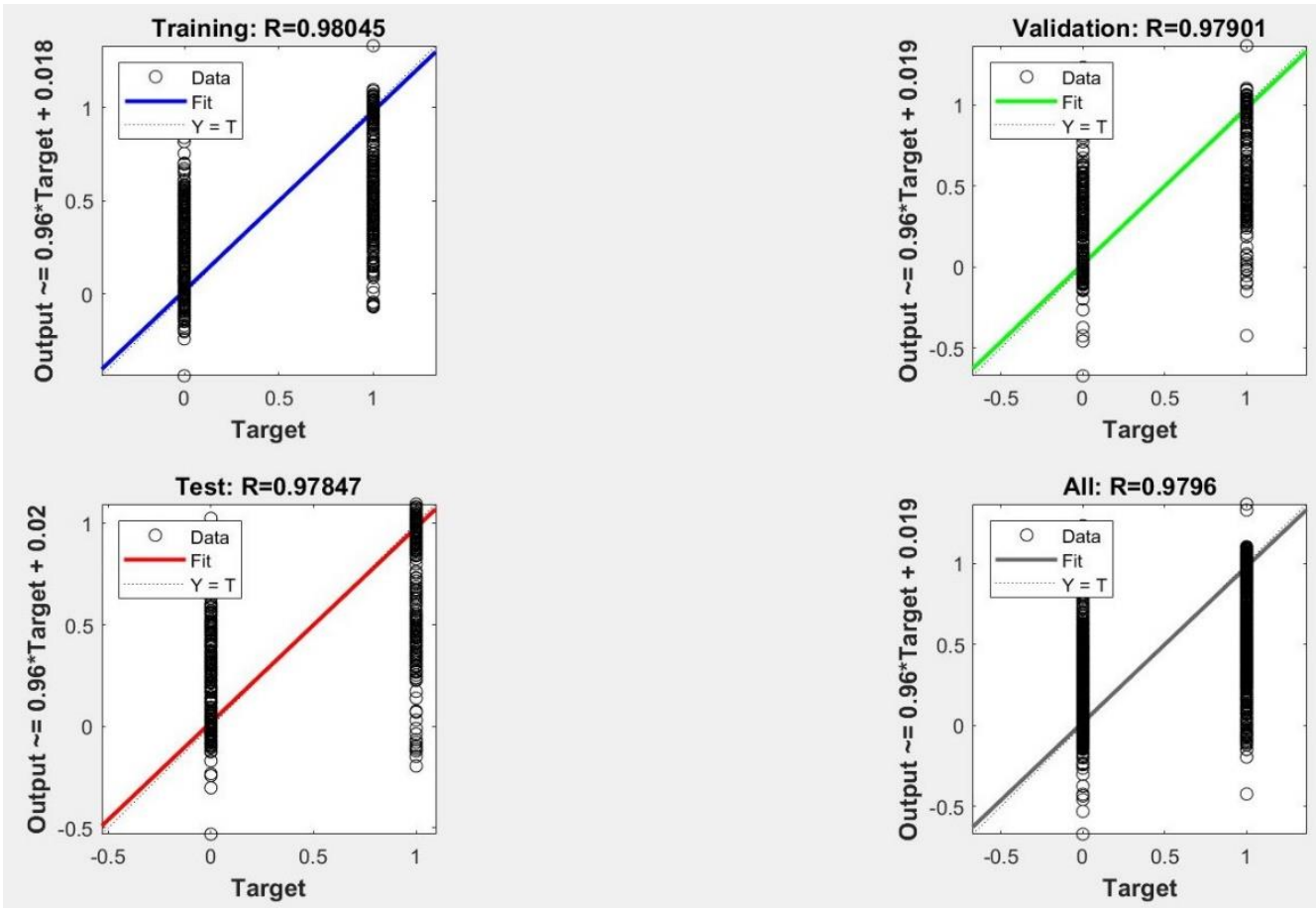

Figure 2: Regression outputs of ANN model for Temperate Forests

The error status during model development is represented in Figure 3. 


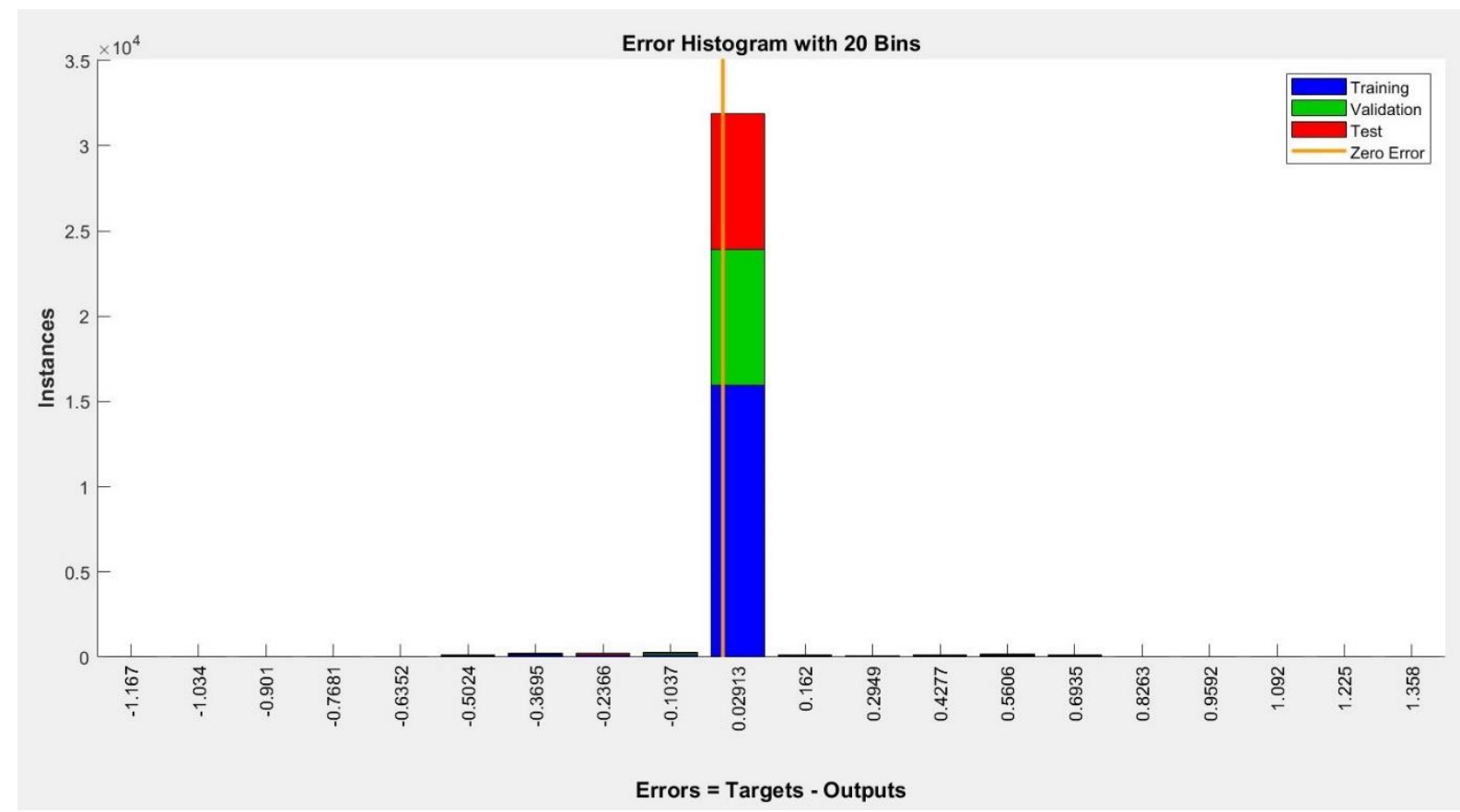

165 Boreal forests

Figure 3: Error Status of ANN model for Temperate Forests

With regression factor of 9.55e-1 and MSE of 2.21e-2, Levenberg-Marquartdt algorithm had the best performance for prediction model development of boreal forests. Sixty percent of the data set related to boreal forests were used for network training; 20 percent of the data set were used in validation and the rest were used for testing step. Figure 4 represents regression in each step. 

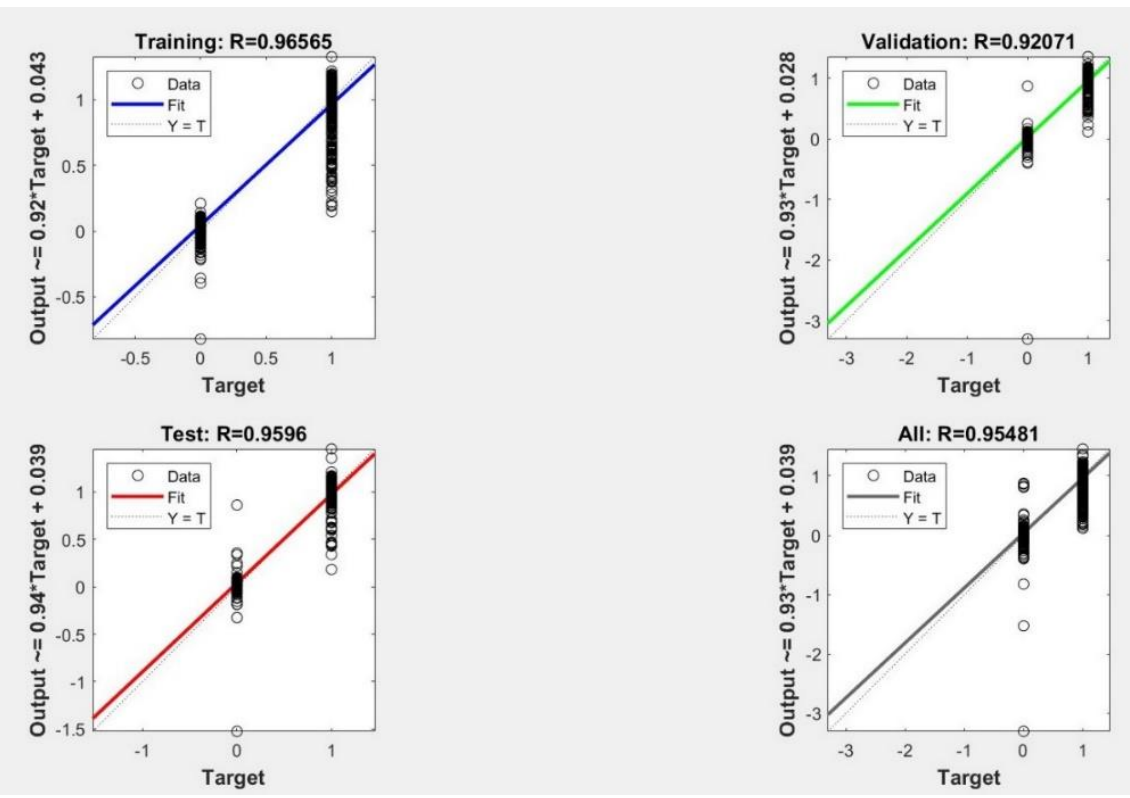

Figure 4: Regression outputs of ANN model for Boreal Forests

The error status during model development is represented in Figure 5.

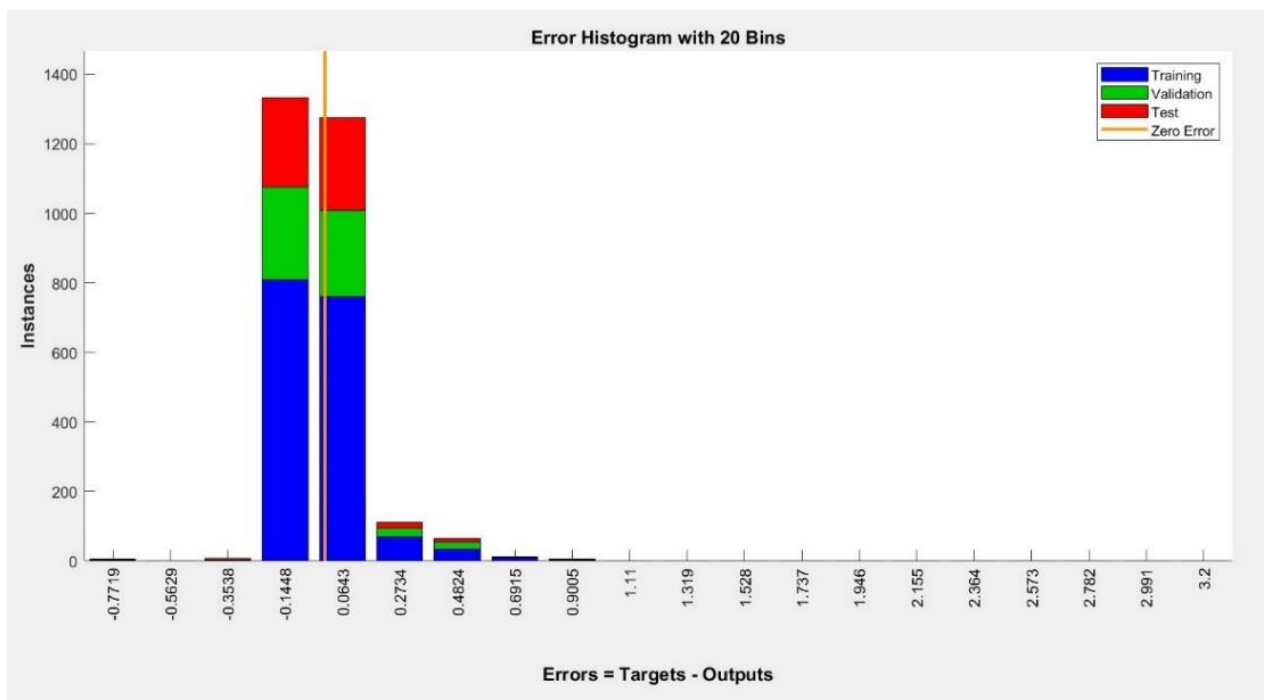

\section{Result analysis}

Figure 5: Error Status of ANN model for Temperate Forests

The sensitivity of the models to temperature variation was analyzed based on non-fire record data sets. For the sensitivity analysis, temperature was increased by 0.1 to 3 degrees of Celsius from past 7 -day average value. 


\section{Temperate forests}

A 0.1-degree Celsius increase in temperature relative to 7-day average temperature before a fire occurrence results in prediction model output of greater than 0.8 for $4.75 \%$ of fire forest cases. The model output for each 0.1 degree Celsius increment is presented in Table 2 and the chart is plotted in the Figure 6.

Table 2: Model output for temperature increments in Temperate Forests

\begin{tabular}{|c|c|}
\hline $\begin{array}{c}\text { Temperature increase relative to 7-day average temperature } \\
\text { before fire occurrence }\end{array}$ & $\begin{array}{c}\text { Percent of forest cases with model output of } \\
\text { greater than } 0.8\end{array}$ \\
\hline 0.1 & 4.75 \\
\hline 0.2 & 4.74 \\
\hline 0.3 & 4.76 \\
\hline 0.4 & 4.78 \\
\hline 0.5 & 0.17 \\
\hline 0.6 & 0.46 \\
\hline 0.7 & 1.45 \\
\hline 0.8 & 6.29 \\
\hline 0.9 & 22.15 \\
\hline 1 & 35.25 \\
\hline 1.1 & 50.64 \\
\hline 1.2 & 77.62 \\
\hline 1.3 & 87.54 \\
\hline 1.4 & 90.71 \\
\hline 1.5 & 92.17 \\
\hline 1.6 & 92.93 \\
\hline 1.7 & 93.45 \\
\hline 1.8 & 93.76 \\
\hline 1.9 & 93.99 \\
\hline 2 & 94.17 \\
\hline 2.1 & 94.30 \\
\hline 2.2 & 94.40 \\
\hline 2.3 & 94.42 \\
\hline 2.4 & 94.49 \\
\hline 2.5 & 94.54 \\
\hline 2.6 & 94.60 \\
\hline 2.7 & 94.62 \\
\hline 2.8 & 94.65 \\
\hline 2.9 & 94.67 \\
\hline 3 & 94.69 \\
\hline
\end{tabular}




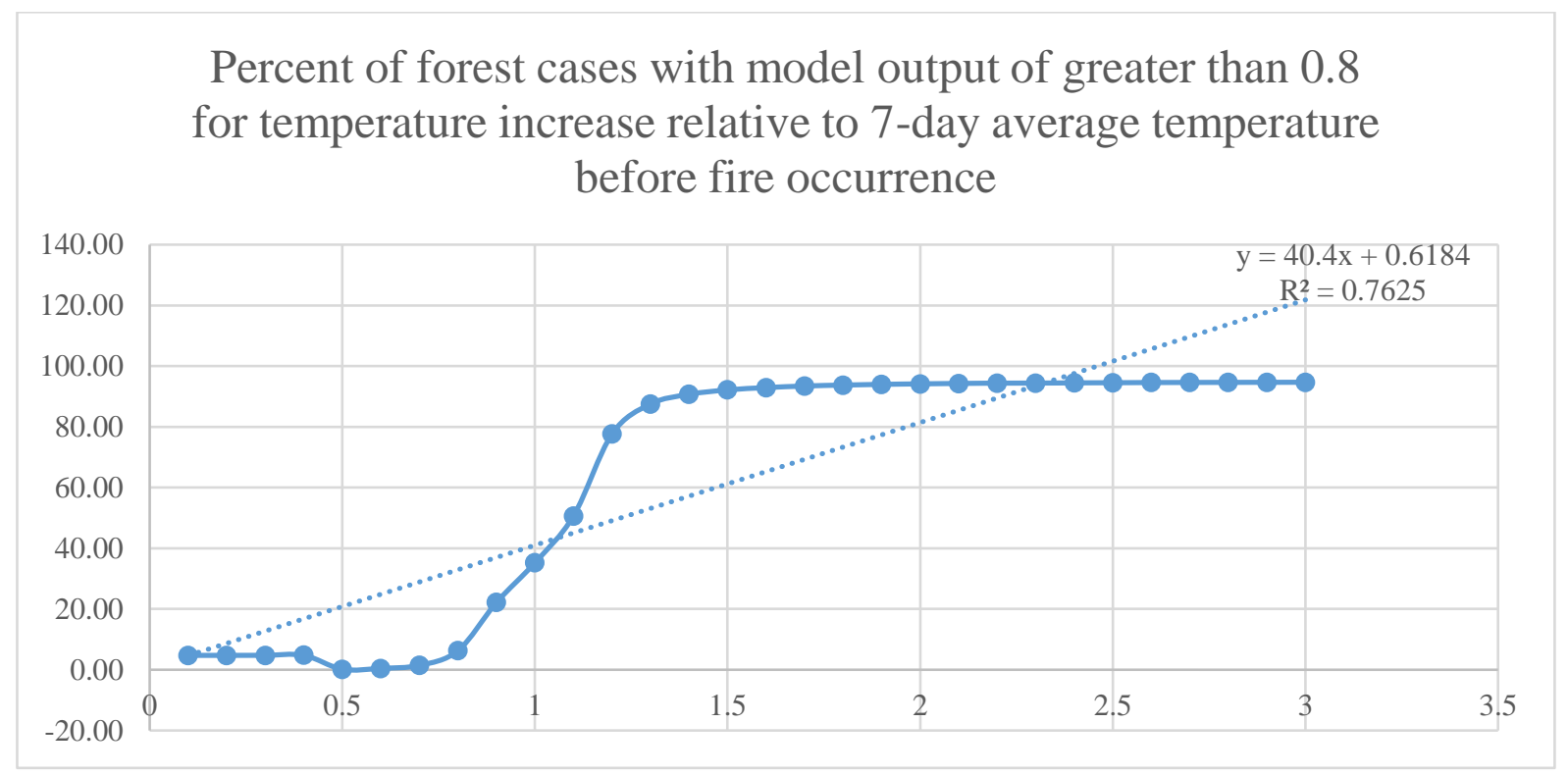

Figure 6: Model output for temperature increments in Temperate Forests

A linear regression was fit to the chart with regression factor of 0.76 .

The average temperature during days with fire occurrence is 14.37 degree of Celsius and is 1.06 degree higher than the 7-day average temperature before fire occurrence which is equal to 13.31 degree of Celsius. Moreover, the Figure 6 shows a 1.1 degree increase in temperature relative to the past 7 -day average results in $50 \%$ of wildfire occurrence.

The curve starts to grow on 0.5-degree increase, and it has the highest growth rate between 0.8 and 1.2 degree increase. Almost $90 \%$ of the fire cases have the prediction model output of greater than 0.8 which means serious fire threat if the temperature increase is higher than 1.3 degree.

\section{Boreal forests}

The model output for temperature increase of less than 1 degree relative to past 7 -day average temperature represents no chance of wildfire in boreal forests. But the non-zero fire forest starts at 2 degrees increase of temperature which ends to $2.62 \%$ of fire forest cases with model output of larger than 0.8 . The model output for each 0.1 degree Celsius increment is presented in Table 3 and the chart is plotted in the Figure 7. 
Table 3: Model output for temperature increments in Boreal Forests

\begin{tabular}{|c|c|}
\hline $\begin{array}{c}\text { Temperature increase relative to 7-day average temperature } \\
\text { before fire occurrence }\end{array}$ & $\begin{array}{l}\text { Percent of forest cases with model output of } \\
\text { greater than } 0.8\end{array}$ \\
\hline 1 & 0 \\
\hline 2 & 2.62 \\
\hline 2.1 & 4.18 \\
\hline 2.2 & 7.59 \\
\hline 2.3 & 11.35 \\
\hline 2.4 & 15.39 \\
\hline 2.5 & 21.56 \\
\hline 2.6 & 30.28 \\
\hline 2.7 & 40.64 \\
\hline 2.8 & 53.55 \\
\hline 2.9 & 63.19 \\
\hline 3 & 71.42 \\
\hline 3.1 & 78.37 \\
\hline 3.2 & 83.05 \\
\hline 3.3 & 86.60 \\
\hline 3.4 & 89.22 \\
\hline 3.5 & 90.85 \\
\hline 3.6 & 92.27 \\
\hline 3.7 & 93.55 \\
\hline 3.8 & 94.54 \\
\hline 3.9 & 95.11 \\
\hline 4 & 95.82 \\
\hline
\end{tabular}




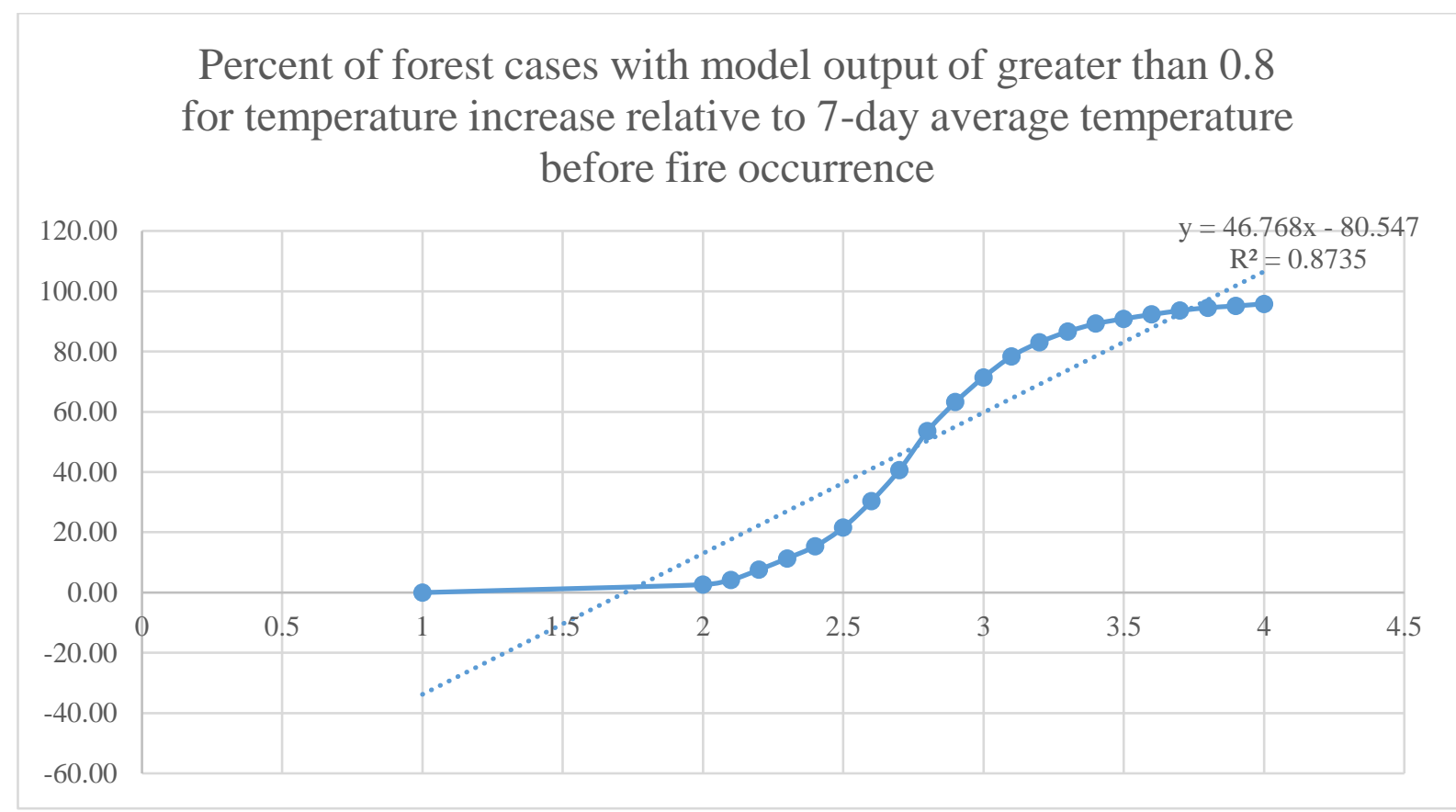

Figure 7: Model output for temperature increments in Boreal Forests

205 A linear regression was fit to the chart with regression factor of 0.87.

The average temperature during days with fire occurrence is 13.78 degree of Celsius and is 0.98 degree higher than the 7-day average temperature before fire occurrence which is equal to 12.79 degree of Celsius. Moreover, the Figure 7 shows a 2.8 degree increase of temperature relative to the past 7-day average results in $50 \%$ of wildfire occurrence.

210 The curve starts to grow on 1 to 2 degrees increase, and it has the highest growth rate between 2.5 and 2.8 degrees increase. Almost $90 \%$ of the fire cases have the prediction model output of greater than 0.8 which means serious fire threat if the temperature increase is higher than 3.5 degree.

\section{Conclusion}

Based on model outputs and fire percentage occurrence in charts of Figure 6 and Figure 7, a temperature interval can be introduced as "transient temperature span" for each forest type. There is high fire occurrence probability if the temperature increase is larger than the transient temperature span during a period of less than 7 days.

In other words, weather forecast in a region is useful to detect fire hazard for the next 7 days. The detection of fire hazard is crucial for responsible organizations to get prepared and manage the resources. The input variables to 
the model include temperature, absolute pressure, relative humidity, wind speed, evaporation, Keetch-Byram

Drought Index, NDVI, soil surface moisture, snow storage, and precipitation.

The transient temperature span is about 0.8 to 1.2 degrees for temperate forests and about 2.5 to 2.8 degrees for boreal forests.

The similarity of the two curves in Figure 6 and Figure 7 suggests that temperature increase is one of the most important causes of wildfires. Moreover, with low values of temperature increase, other input variables have a lot more contributory role in fire prediction rather than temperature. Their roles and their magnitude are suggested in future study.

It is concluded that other variables except temperature are more determinant to predict wildfires in temperate forests rather than in boreal forests. On the contrary, with temperature increase greater than transient temperature span, the wildfire is mostly dependent on temperature while other variables have less important effect on the model output. Like before, with low temperature increase, it is suggested to focus study on variables other than temperature in boreal forests.

So, there is a positive linear relationship between wildfire occurrence and temperature increase. Using weather parameters, it is possible to model the relationship and predict fire cases affected by global warming.

\section{Author contribution}

235 Amir Hossein Sadat Razavi: Conceptualization, Methodology, Data curation, Writing- Original draft preparation, Visualization. Majid Shafie-Pour-Motlagh, Alireza Noorpoor, Amir Houshang Ehsani: Supervision

\section{Competing Interests}

The authors declare that they have no conflict of interest.

\section{References}

Abatzoglou, J. T., \& Kolden, C. A. (2013). Relationships between climate and macroscale area burned in the western United States. International Journal of Wildland Fire. https://doi.org/10.1071/WF13019

Abatzoglou, J. T., \& Williams, A. P. (2016). Impact of anthropogenic climate change on wildfire across western US forests. Proceedings of the National Academy of Sciences of the United States of America. https://doi.org/10.1073/pnas.1607171113

245 Aponte, C., De Groot, W. J., \& Wotton, B. M. (2016). Forest fires and climate change: Causes, consequences and management options. In International Journal of Wildland Fire. https://doi.org/10.1071/WFv25n8_FO 
Catry, F. X., Rego, F. C., Bação, F. L., \& Moreira, F. (2009). Modeling and mapping wildfire ignition risk in Portugal. International Journal of Wildland Fire. https://doi.org/10.1071/WF07123

Davis, R., Yang, Z., Yost, A., Belongie, C., \& Cohen, W. (2017). The normal fire environment-Modeling environmental suitability for large forest wildfires using past, present, and future climate normals. Forest Ecology and Management. https://doi.org/10.1016/j.foreco.2017.01.027

Dennison, P. E., Brewer, S. C., Arnold, J. D., \& Moritz, M. A. (2014). Large wildfire trends in the western United States, 1984-2011. Geophysical Research Letters. https://doi.org/10.1002/2014GL059576

Dey, D. C., \& Schweitzer, C. J. (2018). A Review on the dynamics of prescribed fire, tree mortality, and injury in managing oak natural communities to minimize economic loss in North America. In Forests. https://doi.org/10.3390/f9080461

Duane, A., Kelly, L., Giljohann, K., Batllori, E., McCarthy, M., \& Brotons, L. (2019). Disentangling the Influence of Past Fires on Subsequent Fires in Mediterranean Landscapes. Ecosystems. https://doi.org/10.1007/s10021-019-00340-6

Flannigan, M., Cantin, A. S., De Groot, W. J., Wotton, M., Newbery, A., \& Gowman, L. M. (2013). Global wildland fire season severity in the 21 st century. Forest Ecology and Management. https://doi.org/10.1016/j.foreco.2012.10.022

Flannigan, M., Krawchuk, M. A., De Groot, W. J., Wotton, B. M., \& Gowman, L. M. (2009). Implications of changing climate for global wildland fire. In International Journal of Wildland Fire. https://doi.org/10.1071/WF08187

Hamadeh, N., Karouni, A., Daya, B., \& Chauvet, P. (2017). Using correlative data analysis to develop weather index that estimates the risk of forest fires in Lebanon \& Mediterranean: Assessment versus prevalent meteorological indices. Case Studies in Fire Safety. https://doi.org/10.1016/j.csfs.2016.12.001

Hessl, A. E. (2011). Pathways for climate change effects on fire: Models, data, and uncertainties. In Progress in Physical Geography. https://doi.org/10.1177/0309133311407654

Jaafari, A., Gholami, D. M., \& Zenner, E. K. (2017). A Bayesian modeling of wildfire probability in the Zagros Mountains, Iran. Ecological Informatics. https://doi.org/10.1016/j.ecoinf.2017.03.003

Jaafari, A., Mafi-Gholami, D., Thai Pham, B., \& Tien Bui, D. (2019). Wildfire Probability Mapping: Bivariate vs. Multivariate Statistics. Remote Sensing. https://doi.org/10.3390/rs11060618

Jaafari, A., Zenner, E. K., Panahi, M., \& Shahabi, H. (2019). Hybrid artificial intelligence models based on a neuro-fuzzy system and metaheuristic optimization algorithms for spatial prediction of wildfire probability. Agricultural and Forest Meteorology. https://doi.org/10.1016/j.agrformet.2018.12.015

Jaafari, A., Zenner, E. K., \& Pham, B. T. (2018). Wildfire spatial pattern analysis in the Zagros Mountains, Iran: A comparative study of decision tree based classifiers. Ecological Informatics. https://doi.org/10.1016/j.ecoinf.2017.12.006

Jahdi, R., Salis, M., Darvishsefat, A. A., Alcasena, F., Mostafavi, M. A., Etemad, V., Lozano, O. M., \& Spano, D. (2016). Evaluating fire modelling systems in recent wildfires of the Golestan National Park, Iran. Forestry. https://doi.org/10.1093/forestry/cpv045 
Jolly, W. M., Cochrane, M. A., Freeborn, P. H., Holden, Z. A., Brown, T. J., Williamson, G. J., \& Bowman, D. M. J. S. (2015). Climate-induced variations in global wildfire danger from 1979 to 2013. Nature Communications. https://doi.org/10.1038/ncomms8537

Littell, J. S., Mckenzie, D., Peterson, D. L., \& Westerling, A. L. (2009). Climate and wildfire area burned in western U.S. ecoprovinces, 1916-2003. Ecological Applications. https://doi.org/10.1890/07-1183.1

Moritz, M. A., Parisien, M.-A., Batllori, E., Krawchuk, M. A., Van Dorn, J., Ganz, D. J., \& Hayhoe, K. (2012). Climate change and disruptions to global fire activity. Ecosphere. https://doi.org/10.1890/es11-00345.1

Nami, M. H., Jaafari, A., Fallah, M., \& Nabiuni, S. (2018). Spatial prediction of wildfire probability in the Hyrcanian ecoregion using evidential belief function model and GIS. International Journal of Environmental Science and Technology. https://doi.org/10.1007/s13762-017-1371-6

North, M. P., Stephens, S. L., Collins, B. M., Agee, J. K., Aplet, G., Franklin, J. F., \& Fulé, P. Z. (2015). Reform forest fire management: Agency incentives undermine policy effectiveness. In Science. https://doi.org/10.1126/science.aab2356

Parisien, M. A., Miller, C., Parks, S. A., Delancey, E. R., Robinne, F. N., \& Flannigan, M. D. (2016). The spatially varying influence of humans on fire probability in North America. Environmental Research Letters. https://doi.org/10.1088/1748-9326/11/7/075005

Pérez-Sánchez, J., Senent-Aparicio, J., Díaz-Palmero, J. M., \& Cabezas-Cerezo, J. de D. (2017). A comparative study of fire weather indices in a semiarid south-eastern Europe region. Case of study: Murcia (Spain). Science of the Total Environment. https://doi.org/10.1016/j.scitotenv.2017.03.040

Ramanathan, V., \& Carmichael, G. (2008). Global and regional climate changes due to black carbon. In Nature Geoscience. https://doi.org/10.1038/ngeo156

San-Miguel-Ayanz, J., Moreno, J. M., \& Camia, A. (2013). Analysis of large fires in European Mediterranean landscapes: Lessons learned and perspectives. Forest Ecology and Management. https://doi.org/10.1016/j.foreco.2012.10.050

Seidl, R., Thom, D., Kautz, M., Martin-Benito, D., Peltoniemi, M., Vacchiano, G., Wild, J., Ascoli, D., Petr, M., Honkaniemi, J., Lexer, M. J., Trotsiuk, V., Mairota, P., Svoboda, M., Fabrika, M., Nagel, T. A., \& Reyer, C. P. O. (2017). Forest disturbances under climate change. In Nature Climate Change. https://doi.org/10.1038/nclimate3303

Short, K. C. (2017). Spatial wildfire occurrence data for the United States, 1992-2015 [FPA_FOD_20170508].

Spessa, A. C., Field, R. D., Pappenberger, F., Langner, A., Englhart, S., Weber, U., Stockdale, T., Siegert, F., Kaiser, J. W., \& Moore, J. (2015). Seasonal forecasting of fire over Kalimantan, Indonesia. Natural Hazards and Earth System Sciences, 15(3), 429-442. https://doi.org/10.5194/nhess-15-429-2015

Srivas, T., De Callafon, R. A., Crawl, D., \& Altintas, I. (2017). Data Assimilation of Wildfires with Fuel Adjustment Factors in farsite using Ensemble Kalman Filtering. Procedia Computer Science. https://doi.org/10.1016/j.procs.2017.05.197

Stavros, E. N., Abatzoglou, J., Larkin, N. K., Mckenzie, D., \& Steel, E. A. (2014). Climate and very large wildland fires in the contiguous western USA. International Journal of Wildland Fire. 
https://doi.org/10.1071/WF13169

Vilà-Vilardell, L., Keeton, W. S., Thom, D., Gyeltshen, C., Tshering, K., \& Gratzer, G. (2020). Climate change effects on wildfire hazards in the wildland-urban-interface - Blue pine forests of Bhutan. Forest Ecology and Management. https://doi.org/10.1016/j.foreco.2020.117927

Vilar, L., Garrido, J., Echavarría, P., Martínez-Vega, J., \& Martín, M. P. (2019). Comparative analysis of CORINE and climate change initiative land cover maps in Europe: Implications for wildfire occurrence estimation at regional and local scales. International Journal of Applied Earth Observation and Geoinformation. https://doi.org/10.1016/j.jag.2019.01.019 